\title{
COPIM•
}

\section{Data Books \& Data Bodies: Performing Archival Data differently}

Julien McHardy, Kat Jungnickel, Rebekka Kiesewetter, Ellen Fowles

Published on: Oct 11, 2021

License: Creative Commons Attribution 4.0 International License(CC-BY 4.0). 
Politics of Patents, or POP, is a research project headed by Kat Jungnickel looking at 200 years of clothing patents to reveal some of the hidden ideas, practices and histories that are inscribed into people' s dress. Working with over 370,000 patents, Kat and her team have unearthed the stories and designs of many lesser-known inventors who pushed and struggled to change how people' s dress addresses political needs and desires for liberation, safety, containment and expression. The archive of patents in this work is not just a record of what was, but a resource that opens up and expands normative understandings of the world at different times.

One of the project' s questions is how large amounts of seemingly dry and dusty data can be brought into experience, on bodies, to literally craft different bodies and possibilities. They are exploring this by combining research with reconstruction; making and wearing a collection of historic costumes from the archive. The question speaks to the work of Julien McHardy and his colleagues Rebekka Kiesewetter, Janneke Adema, Gary Hall, Tobias Steiner, and Simon Bowie at COPIM' s experimental publishing group, exploring books as intermediaries that can anchor and hold previously published data, text and analysis as well as collectives and practices.

At COPIM' s experimental publishing group, we' re especially interested in the book as a dynamic conduit between archive and interpretation. We think of books that relate digital archival material, and data to interpretation as Data Books. We are interested in where the archive ends and the book starts, and how new technologies and open copyright regimes allow blurring that boundary between data and analysis in productive ways. With that in mind, we experiment with relating databases, previously published sources, narrative and analytical storytelling in new ways. The book, we explore as a site of archive/reading/writing interference; an interface for bringing data into shared experience; transforming data from disembodied information to situated, embodied, relational, and negotiated knowledges.

With that in mind, we ask ourselves how to perform data differently? Kat and her team approach this question with thread and needle in hand, sewing, cutting and wearing historical designs, crafting analysis and items of clothing at once. In the Experimental Publishing group, we' re exploring books as experiential spaces, that can hold and mediate different positions. Together we are exploring how data comes to life and available for crafting new ways of knowing, being and togetherness. In short, we wonder how to perform data differently, how to approach the archive as a lively gathering, and how to share it in book form. 
As a first step, Kat and Ellen Fowles, the Research Assistant from POP, along with Julien and Rebekka from the Experimental Publishing Group organised Performing Archival Data Differently, taking place on

The Internet. 17 June 2021. 16-18h CEST.

The online workshop gathered an international group of scholars, writers, dancers, artists, publishers and archivists from Sweden, the Netherlands, Germany, and the UK, for a two-hour session. Thanks, Joana Chicau, Adele Mason-Bertrand, Simon Worthington, Janneke Adema, Claudia Di Gianfrancesco, Katja May, Silvia Bombardini, Marta Musso, Åsa Ståhl, Kristina Lindström, Gary Hall and Toby Steiner for joining us! We were so glad to have you, because, in one way or another, you all work with performing data differently, often using experimental forms of publication.

Together we wondered how one might perform data bodies and archives differently? And how making a difference in how data is performed can affect what kinds of knowledge objects and subjects are performed into being? We also asked how digital tools and machine reading/writing change the relationship between data and text. What will Data books look like, that blur the boundaries between archive and text, analysis and data, qual and quant materials? We worked with two sets of materials:

\section{The workshop as a site of data performance}

First, we explored the online workshop as a site where data and bodies are performed in particular ways. Where do the camera's point and what is framed? What ethics govern the encounter? And how do bodily needs and presence enter the seemingly virtual transmission? 


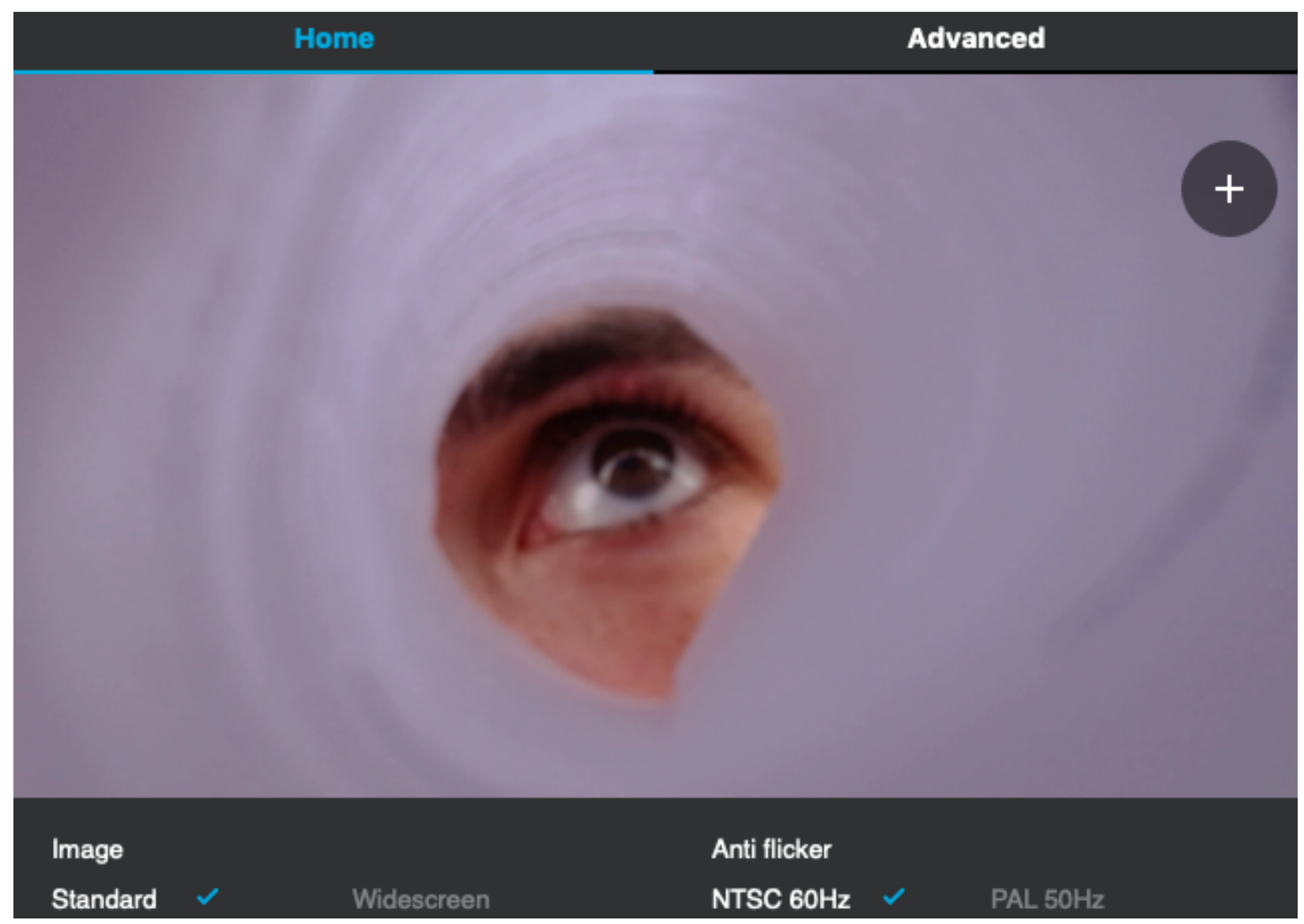

Video meetings mask and direct. Experimenting with camera framings and positions changes space, togetherness and possibilities. 


\section{Performing data begins with our practices in this workshop. Performing data differently requires an ethics of engagement. For the purpose of this meeting and as a starting point we kept it simple:}

\section{Ethics of Engagement}

1 FOCUS - limit distractions and avoid multitasking, concentrate and commit to the task at hand.

2 SIMPLICITY - be thoughtful when discussing complex terms, and don't assume that everyone will understand. Speak up and ask for further clarity.

| 3 ASK - there are no stupid or unimportant questions. Feel free to speak out, or you can ask through the chat function (please be aware this is not private).

4 RESPECT - we want everyone to have their voice heard and valued. There will be a tolerance of differences, and everyone should contribute to a safe and non-judgemental environment, agree to disagree.

5 SHARING - anyone who comes to a meeting is free to use information from the discussion but cannot reveal who made the comment. It is designed to increase openness of discussion, Chatham House Rules.

\section{How data is performed, and how data is engaged and engages us is an} ethical question.

\section{Grounding}

Close your eyes.

Sit in a comfortable position, your feet firmly on the ground. Feel how your feet touch the floor, how parts of your body touch the chair you' re sitting on, Feel your hands on the keybord of your computer, or resting on the table or in your lap,

Sense your height, your width, your weight, your physical presence.

Feel your clothes rub against your skin,

Feel your heartbeat, the rhythm of your breath.

Breath deep into your center.

Feel the place you are at mentally, energy- and mood-wise. Sense the space in and the space around you.

Notice the walls, the ceiling, the sky above it.

Feel what' s outside the window. 
Notice smells and sounds.

Feel the floor under your feet.

Feel the fundaments you' re grounded in.

Sink deeper into the ground.

Feel through the layers and sediments of the built, of time, of history - your history, the one of others, common histories...

Slowly come back, open your eyes.

I hope you feel centered in your own space and are ready to connect to our shared space.

This grounding exercise lead by Rebekka Kiesewetter aimed to bring bodies into the frame of the seemingly virtual video workshop.

\section{Performing Patents}

After setting the conditions of the encounter, we invited people to work with a small subset of mask patents from the archive of clothing patents assembled by the Politics of Patents Project. This sub-set focusing on masks was the material for experimenting handson with how data is performed. 


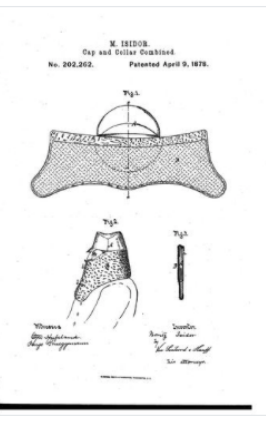

1878 - US202262A muff.pdf
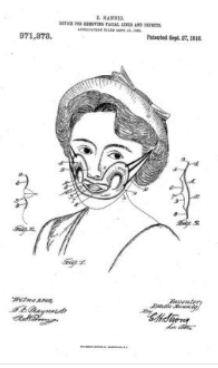

1910 - US971...d defects.pdf

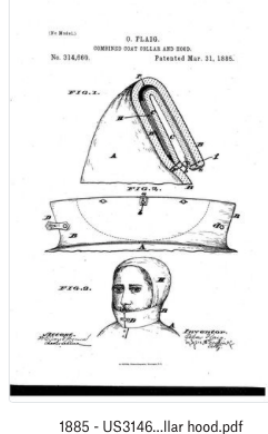

1885 - US3146...llar hood.pdf

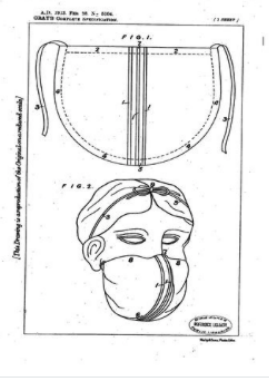

1913 - GB1913...espirator.pdf

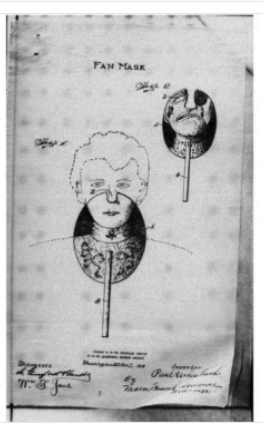

1903 - CA8451...fan mask.pdf

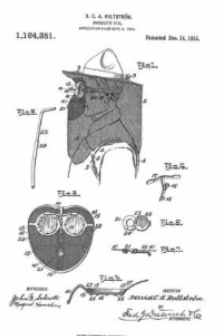

1916 - US1164...uito Veil.pdf

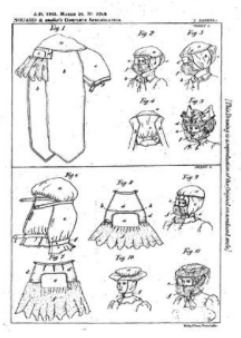

1903 - GB1903...ing Mask.pdf

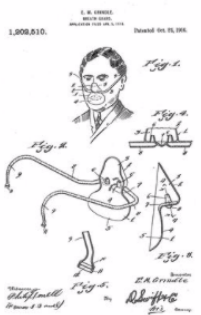

1916 - US1202...th guard.pdf

Some of the mask patents we shared. You can download the full set of mask patents.

To orient the exploration we shared a Performing data map. 


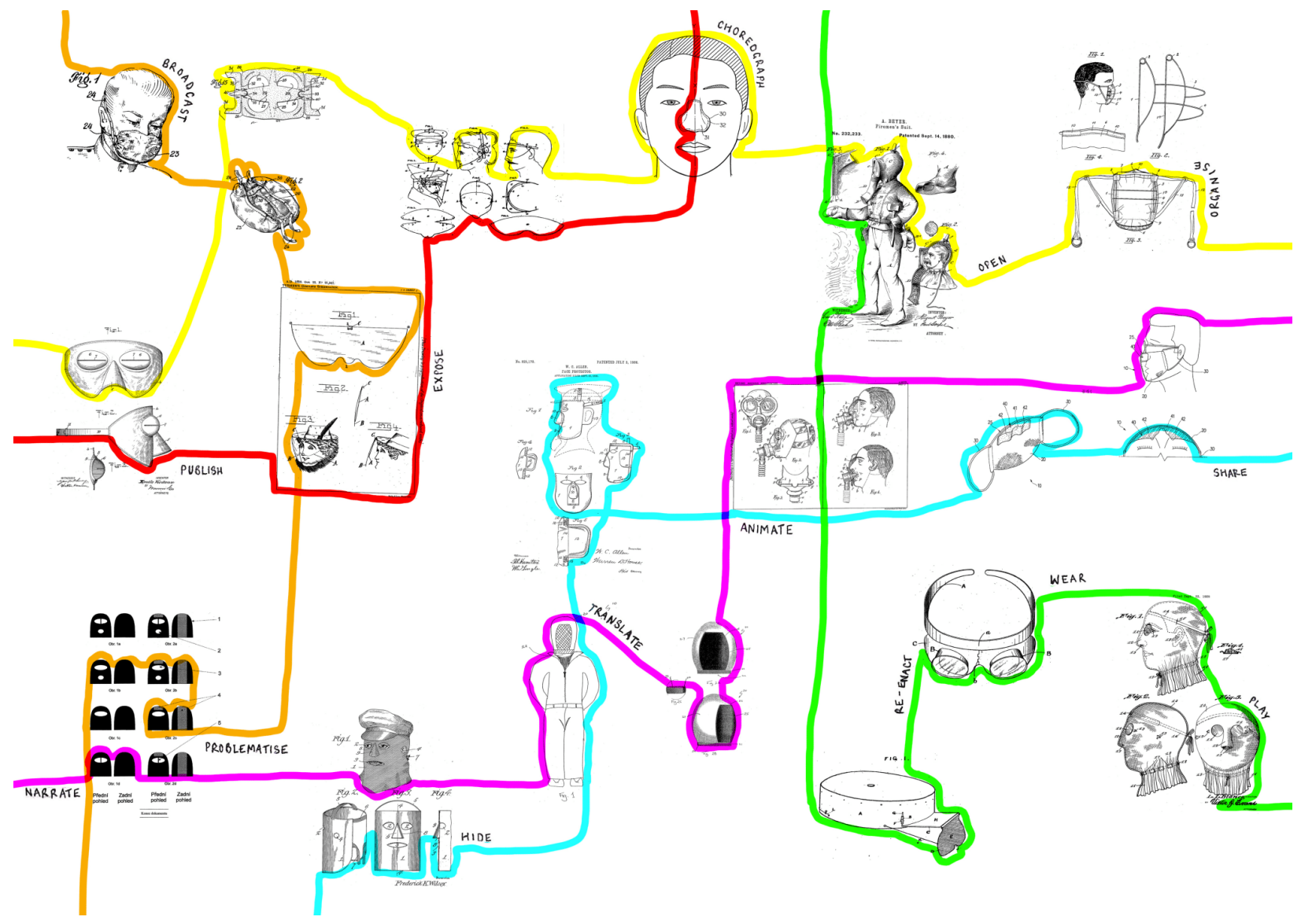

Fowles, Ellen. (2021). Performing Data Differently

Map. Zenodo. https://doi.org/10.5281/zenodo.5541339

We also shared audio samples on data performance - produced in collaboration with Vena, the Indian English voice of Apple' s text-to-voice engine - to decenter text and image:

\section{Visit the web version of this article to view interactive content.}

Apple's Veena \& Julien McHardy (2021) Performing data differently

Working together apart, we translated the provided mask patents into wearable or otherwise performable masks while listening to the workshop's Mask Making Music playlist; the soundtrack for our mask making session.

We had an excellent variety of material responses to the mask making task. Some participants used what was within their reach, including orange peel, toilet roll and indoor plants. Others printed and manipulated the paper patents themselves, using 
watercolours, chopsticks and fabric sheets. There was an interesting relationship between physical crafting and more digital experimentation.

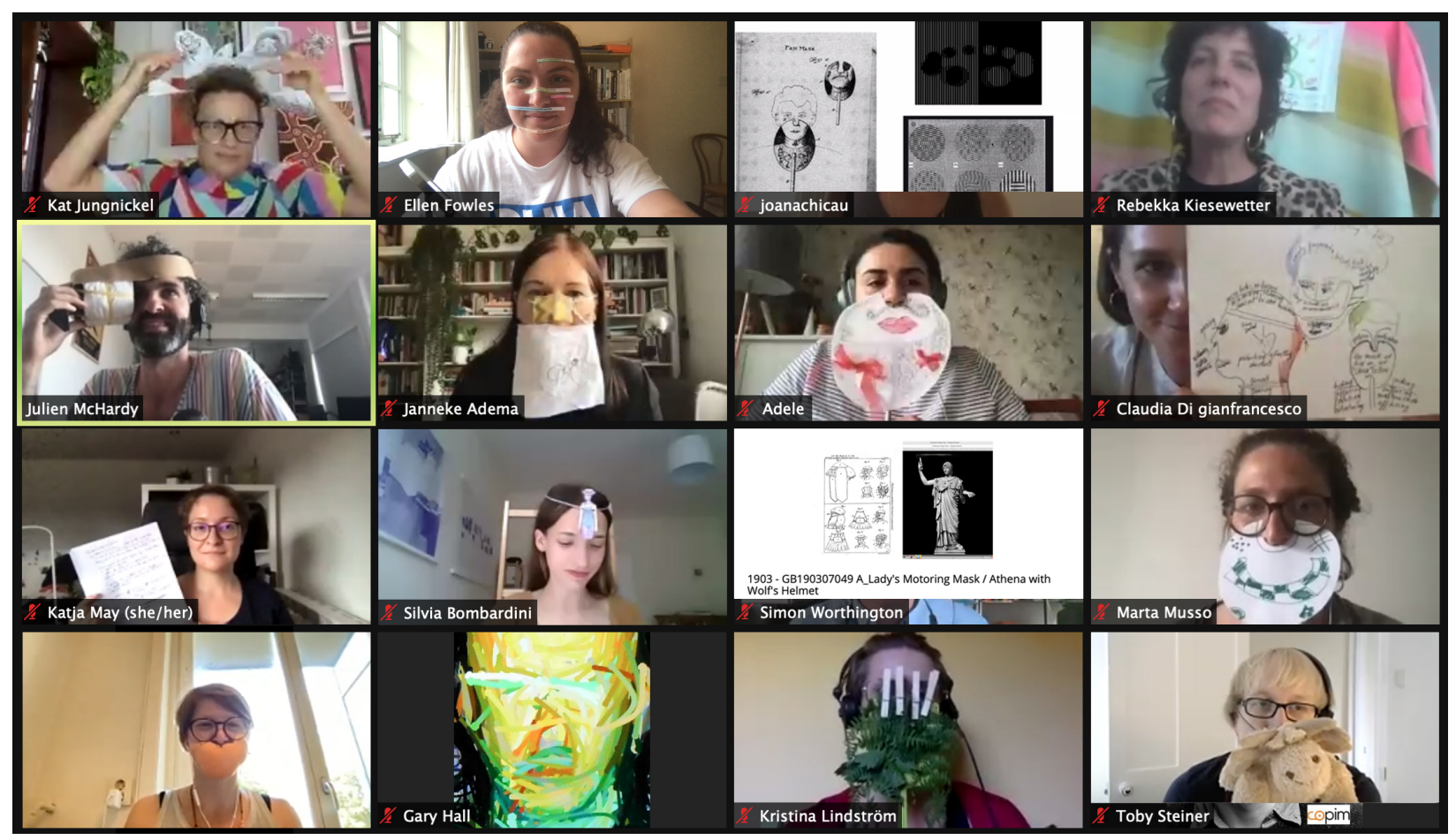

What a gathering! Some of the masks people fabricated during the workshop.

Simon Worthington for example envisioned (two) archives into a conversation, based on user input or algorithmic matching. To demonstrate the approach Simon juxtaposed historical mask patents from the POP database with The Census of Antique Works of Art and Architecture Known in the Renaissance http://www.census.de in a parallel montage.

\section{Visit the web version of this article to view interactive content.}

Simon Worthington (2021) archive collage

1916 - US1164351 A Mosquito Veil / Amoretti Playing with a Mask 1903 - GB190307049 A Lady's Motoring Mask / Athena with Wolf's Helmet 1903 - GB190307049 A_Lady's Motoring Mask / Athena with Wolf's Helmet

The chat, as is often the case, formed another layer of the encounter. Here are some snippets highlighting interesting projects that people shared.

16:25:55 From Simon Worthington to Everyone : http://www.census.de

16:27:16 From Simon Worthington to Everyone : decolonize Classicism 
16:27:22 From Gary Hall to Everyone : Also reminds me of the Box Man: https://www.goodreads.com/book/show/9999. The Box Man

16:28:41 From Åsa Ståhl to Everyone : thank you so very much everyone - this was great! i unfortunately have to leave - will go through the portal into other worlds with my mask on...

16:49:11 From Janneke Adema to Everyone : The Werkbank is something I really like as an example to add to the archive https://vimeo.com/157990864

16:52:33 From Simon Worthington to Everyone : Lozana Rossenova's LOD work is interesting - https://sites.rhizome.org/artbase-redesign/index.html

16:53:24 From Claudia Di gianfrancesco to Everyone : The dream archive is also quite interesting - https://www.internationalarchiveofdreams.com

16:53:44 From Toby Steiner to Everyone : https://www. baclac.gc.ca/eng/discover/biography_people/mcluhan/Pages/mcluhan.asp $\underline{x}$

16:56:58 From Toby Steiner to Everyone : and https://discoverarchives.library.utoronto.ca/index.php/marshallmcluhan-papers

16:57:34 From joanachicau to Everyone : on the performative aspect - it maybe interesting to intersect with score making / systems of notations; some refs. That come to mind: http://olga0.oralsite.be/oralsite/pages/What's_the_Score/?/edit/ + https://theconceptbank.org/ + http://mindthedance.com/

16:58:06 From Marta Musso to Everyone : You may be interested in the portal I work for: it aggregates the catalogues of 1000s of archives across Europe to make them searchable in one go www.archivesportaleurope.net

17:02:04 From Kat Jungnickel to Everyone : All great refs, thanks everyone

16:58:40 From Marta Musso to Everyone : (Mostly national and city archives, but there is a very big variety - including a lot on fashion) I love documents and the way in which we approach sources and original documents to trying and understand the truth; thanks to my work for Archives Portal Europe, I am well aware that primary sources can be of any sort, and related to all possible topics. However, as a historian, I focus on international economic history, so closer to social sciences than to the arts and humanities; I only let documents from my personal research speak to me, I only found meaning in my small niche. Thanks to this workshop, I did not only understand on a rational level, but felt almost as a revelation, how much creativity and inspiration can come from archival documents - even in this case, with material that was completely opposite to what is my job and my training.

17:05:20 From Julien Mchardy to Everyone: Thanks for your kind words Marta, and for performing the archive differently with us!!! 
17:06:02 From Gary Hall to Everyone : Thank you

17:06:06 From Katja May (she/her) to Everyone : Thanks everyone!

17:06:06 From joanachicau to Everyone : Thanks!

Thanks indeed. We will continue our collective exploration of performing data differently, and of experimental books as sites of data performance. You can follow us here or at the Politics of Patents blog.

Header image: Fowles, Ellen. (2021). Performing Data Differently

Map. Zenodo. https://doi.org/10.5281/zenodo.5541339 